\title{
Social media usage for neurointerventionalists: report of the Society of Neurolnterventional Surgery Standards and Guidelines Committee
}

\author{
Kyle M Fargen, ${ }^{1}$ Seon-Kyu Lee, ${ }^{2}$ Maxim Mokin 두, ${ }^{3}$ Yasha Kayan, ${ }^{4}$ \\ Reade De Leacy ${ }^{0},{ }^{5}$ Fawaz Al-Mufti, ${ }^{6}$ Sameer A Ansari, ${ }^{7}$ Neil Haranhalli, ${ }^{8}$ \\ Charles J Prestigiacomo, ${ }^{9}$ Clemens M Schirmer $(1),{ }^{10}$ Justin F Fraser $(1), 11$ \\ Steven W Hetts (1), ${ }^{12}$ SNIS Standards and Guidelines Committee, SNIS Board of \\ Directors
}

For numbered affiliations see end of article.

\section{Correspondence to} Dr Steven W Hetts, Radiology and Biomedical Imaging, University of California San Francisco, San Francisco, California, USA; steven.hetts@ ucsf.edu

Received 4 January 2021 Revised 9 February 2021 Accepted 14 February 2021 Published Online First 15 March 2021
Check for updates

(C) Author(s) (or their employer(s)) 2021. No commercial re-use. See rights and permissions. Published by BMJ.

To cite: Fargen $\mathrm{KM}$, Lee $\mathrm{S}-\mathrm{K}$, Mokin $\mathrm{M}$, et al.

J Neurolntervent Surg

2021:13:674-678.

\section{ABSTRACT}

The purpose of this publication is to provide a review of social media usage by neurointerventionalists. Using published literature and available local, regional, and national guidelines or laws, we reviewed data on social media usage as it pertains to neurointerventional surgery. Recommendations are provided based on the quality of information and conformity of medico-legal precedent and law. Social media is a growing entity as it is used both promotionally and educationally. Neurointerventionalists may post de-identified radiographic images with discussions, but should be conscientious and adhere to applicable laws and regulations, strict ethical codes, and institutional policies.

\section{INTRODUCTION}

Social media are web-based platforms through which individual or institutional, public or semipublic, or anonymous profiles may electronically communicate and exchange information. ${ }^{1}$ Facebook is the most widely used (69\%) social media platform by US adults ( $>18$ years old) as of $2019,{ }^{2}$ but several other widely used social media applications exist, including Instagram, Pinterest, LinkedIn, Snapchat, Twitter, WhatsApp, Reddit, and Tumblr. Social media has become ubiquitous in everyday life, and its role in medicine is expanding. There are numerous opportunities that social media affords to our personal and professional lives including developing and maintaining immediate connections with not only friends and family, but also with patients, co-workers, and professional colleagues. Social media can also be used as an advertising platform for physician practices and institutions. Other positive social media applications in medicine include the promotion of public health, education of patients and trainees, tools for research collaborations, professional networking, and practice development. Social media presence is associated with higher academic impact metrics for both neurosurgical departments and journals. ${ }^{3}$

There is a growing use of social media in the neurointerventional community for educational and research efforts. This includes expert physician guidance in an online discussion about acute stroke intervention for patients and their families, ${ }^{4}$ similar to educational content posting by our colleagues or trainees in other medical fields. ${ }^{56}$ In addition, some have utilized social media as research-specific platforms designed to connect and coordinate academic physician research. $^{78}$

The potential benefits of social media utilization by physicians must be balanced with the potential risks and ethical concerns. Most notably, these concerns include the loss of privacy and violations of government rules or institutional policy. Additional risks include the inadvertent spread of non-peer-reviewed information, a presumption of individual expert opinion as a standard of care, exposure of unprofessional or potentially unprofessional personal activities, and, for all of the above reasons, diminishing public trust in our specialty. This manuscript aims to guide neurointerventionalists to mitigate these potential risks and employ the power of social media for the benefit of our providers and patients.

\section{METHODS}

Authors performed a review of published medical literature on social media utilization in medicine and reviewed academic medical institutional policies governing social media posts across a variety of geographical and demographic settings in the USA. The authors reviewed and identified important social media topics of interest to the readership. These included: best physician practices regarding social media usage; Health Insurance Portability and Accountability Act (HIPAA) considerations; issues relating to universities, institutions and hospitals; patient consent for social media posts; medico-legal issues of social media and 'expert opinion'; and ethics of social media in marketing. Published literature queries were then performed using Pubmed and public domain search engines by committee members assigned each topic, and recommendations were drafted based on search results. The subcommittee then compiled, reviewed and edited content for consistency. To supplement the literature review, risk management professionals and medical ethics experts at many of the authors' institutions were also consulted. Recommendations for the ethical usage of social media were provided based on available evidence, when present, or based on agreement among authors regarding best 
practice based on ethical considerations when limited evidence was available.

\section{SPECIFIC CONCERNS/GOOD PRACTICE}

Arguably, the riskiest element of social media usage is the permanence of the content that is uploaded. Once photographs, videos, or text posts are submitted online, they are irrevocable. ${ }^{9-11}$ The posting body (physicians or institutions) has no control to amend previously posted content. The information can be disseminated at will to infinitely large and possibly unintended audiences. ${ }^{12} 13$ Even if the content has been de-identified, it could potentially be traced back to specific patients if the content contains sufficiently unique identifiers such as a particular time period (date of service is protected health information (PHI)), institution, practitioner or limited geographic reach (a zip code is PHI). Therefore, reckless social media usage can blur professional boundaries, serve as a conduit for displaying unprofessional behavior, contribute to an irreversibly infamous online image, and subsequently lead to fines, litigation, and imprisonment. ${ }^{14}$ According to the Department of Health and Human Services, the majority of HIPAA and state privacy violations from recent years have occurred from employees mishandling protected health information, much of which stems from inappropriate social sharing. ${ }^{15}$ The potential consequences of unprofessional behavior on social media are not insignificant. For example, disciplinary actions by the State Medical Board, such as restriction, suspension, or revocation of a medical license, have occurred for physician violations of online professionalism in $56 \%$ of State Medical Boards in the USA. ${ }^{16}$ Also, $14 \%$ of the UK General Medical Council investigations regarding doctors' social media usage between 2015-2017 resulted in their registrations being suspended or restricted. ${ }^{17}$

The American Medical Association has provided official guidelines for the ethical and appropriate use of social media: (1) maintaining patient confidentiality, (2) being aware of privacy settings on social media platforms, (3) adhering to appropriate boundaries with patients, (4) providing accurate and truthful information, (5) avoiding anonymity of the content poster, and (6) the importance of maintaining separate personal and professional profiles. ${ }^{15}$ Also, other guidelines suggest minimizing online interactions with patients and being familiar with hospital and institutional policies on social media. ${ }^{9} 1218$ Furthermore, when posting details and indications of specific procedures, one should encourage their audience to seek professional consultations and provide appropriate disclaimers that the provided information may not directly apply to their needs or concerns. ${ }^{10}$

\section{HIPAA}

The Privacy Rule of HIPAA summarizes national regulations on the use and release of Protected Health Information (PHI). This rule covers patient rights, safety, and disclosures of certain personal information without patient authorization. Box 1 lists the 18 categories that are considered identifiable information according to HIPAA. All of these identifiers must be removed from the media post to comply with regulatory rules. Given the nature of social media posts, special attention should be paid to the first two and last three items on that list. There are currently no well-defined rules regarding the release of any identifiable information on social media if verbal agreement to share such information was obtained from the patient, though written HIPAA waivers are acceptable. Unlike medical charts or scientific journals, social media platforms do not provide an opportunity for documentation of consent. Figure 1 provides
Box 1 Categories of identifiable information under the HIPAA Privacy Rule*

1. Patient name

2. Addresses (any subdivisions smaller than states such as street, city, county, and zip code)

3. Dates (except years) directly related to an individual (birthday, admission or discharge dates, death dates, and exact ages of individuals older than 89 years of age

4. Telephone number

5. Fax number

6. Email address

7. Social Security number

8. Medical record number

9. Health plan beneficiary number

10. Account number

11. Certificate and license number

12. Vehicle identifiers

13. Device identifiers and serial numbers

14. Website URL

15. IP address

16. Biometric identifiers (fingerprints, voiceprints, iris and retina scans)

17. Photographs (face photos or other photos that could identify the patient)

18. Any other characteristics that could identify the patient

*Beware embedded information-for example, date of post, geolocation, background items in photos, all of which can lead to personally identifying information about a patient.

HIPAA, Health Insurance Portability and Accountability Act.

examples of social media posts that comply with the HIPAA Privacy Rule. Examples of common regulator violations are also shown.

While most physicians know the need to exclude directly identifiable PHI such as names or medical record numbers from social media posts, the date of the encounter is probably more likely to be overlooked. Procedure or admission dates constitute PHI and may be used to identify an individual patient in combination with other information. Should cases be posted, the text should not identify a date or time and must not allow for direct inference. Terms such as 'yesterday,' 'last night,' 'this morning,' or 'last week' should be omitted. Similarly, images of the patient, radiological studies, computer monitors, the patient's room, or the procedure room must not include PHI, or other individuals/ patients who have not consented to be photographed for the post in the background. Careful inspection and editing of all posted images are highly recommended to ensure that images are devoid of any identifying features or descriptors, and that no patient or employee rights are violated.

\section{Issues relating to universities, hospitals, and other institutions}

Many universities and hospitals now establish designated marketing departments that are responsible for the creation, review, and approval of social media information representative of the affiliated institution. In many hospitals and institutions, employees (including treating physicians) are not allowed to create social media profiles, webpages, podcasts, or similar material that could be perceived as being 

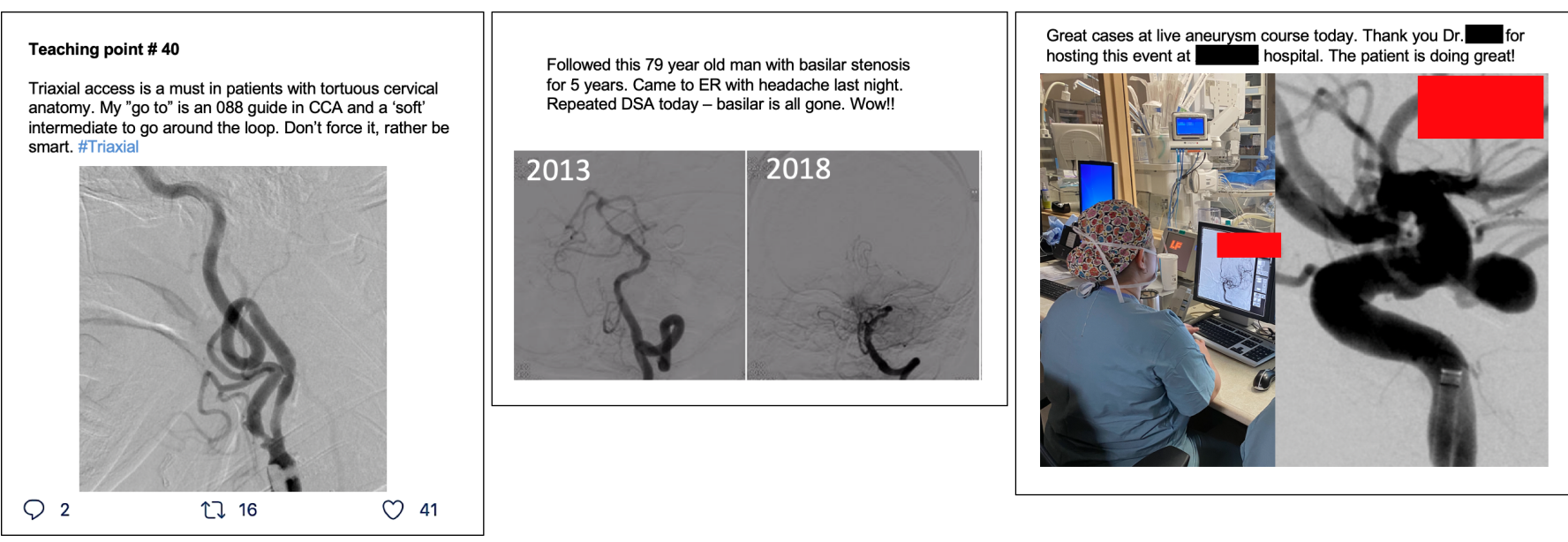

Figure 1 Examples of social media posts with variable compliance of the Protected Health Information rule. These examples are based on real posts found on social media and have been edited to protect the identity of the patients and physicians. The first post (left) provides a concise teaching point without revealing any identifiable information. The post is in compliance with HIPAA guidelines. The second post (middle) is not in compliance as it reveals the date of service ('last night' and 'today'), both of which should be removed. While mention of the year on the two angiography images is not a violation, labeling the initial image as 'baseline' and the second as ' 5 years later' is preferred. Additionally, using a patient age range instead of the exact age is preferred to protect patient anonymity. In the third post (right), a photograph of the angiography suite includes monitors showing cerebral angiographic runs with patient information. Zooming in on the photograph, the patient's medical record number, age and date of birth can be revealed. We have blocked these with red boxes. All potential identifiers need to be removed from the workstation screen before taking a photograph. Alternatively, the photograph may be edited as in the shown image when posted. Finally, consent should be obtained from staff or patients that appear in the images before posting. CCA, common carotid artery; DSA, digital subtraction angiography; ER, emergency room; HIPAA, Health Insurance Portability and Accountability Act.

representative of the institution unless approved by the marketing department.

If one wishes to express a personal opinion, including discussing hospital or university-related matters, it should be clearly stated that the post represents a personal opinion rather than speaking on behalf of the employer or any of its related businesses or organizations. Similar guidance applies when expressing personal opinions that may be erroneously perceived by the public as statements on behalf of professional medical societies. Some institutions encourage or may require employees to provide a disclaimer stating that the views expressed are personal opinions. Also, individual posts should be carefully reviewed and must not disclose non-public employer information. A post identifying its author as associated with a hospital or university may create perceptions not consistent with its values or professional standards. ${ }^{19}$ Given the ease of connecting medical providers with the institutions at which they practice through online searches, social media posts may be considered 'co-branded' by both the provider posting on-line and the institution at which they practice. ${ }^{20}$ Thus, it is recommended that providers planning to establish a social media presence that references their clinical practice should discuss this effort with their institutions to ensure compliance with local regulations. Institutions may also use inappropriate social media posts as a basis for disciplining or terminating employed physicians.

\section{Consent for social media posts}

A major potential issue surrounding the posting of patient information on social media is that of consent. Here, we are referring to consent that is typically required under state privacy laws, as opposed to HIPAA. Peer-reviewed scientific journals, which are predominantly viewed by members of the medical community for educational purposes, often have stringent requirements for patient information/image publication. Such rules are intended to avoid liability under state privacy laws and may have the additional beneficial effect of protecting physician authors from violating HIPAA. For instance, the New England Journal of Medicine requires patient consent for 'Images in Clinical Medicine' that may allow for patient identification. The Journal of the American Medical Association also requires written consent to publish patient descriptions, photographs, or videos if the patient can be identified. The Journal of Neurointerventional Surgery, along with all BMJ publications, goes a step further and requires written patient consent to publish patient information in small case series, regardless of whether the information could potentially identify a patient.

Social media posts, in contrast to journal submissions, have the potential for much broader exposure to both medical and non-medical audiences under auspices not related to education. Given the widespread dissemination of online posts, this audience may include the patient, their family members, co-workers, and others with vested interests in identifying vulnerable patients. Therefore, it is logical that the standards for the lawful and ethical social media posting of patient information or images should be even higher than for scientific articles submitted to a peer-reviewed journal.

It is recommended that healthcare professionals obtain informed consent and HIPAA authorizations from the patient before posting case-specific information, images, or video on social media. It would also be considered good practice to report that patient consent/authorization was obtained before posting. In instances where patients or their family members ask that a post be withdrawn and deleted, their wishes must be respected and the post should be removed.

There are additional ethical considerations in obtaining consent from a patient or family to use patient-specific information or medical images in social media platforms. If the consent for social media is obtained simultaneously while 
obtaining consent for a proposed surgery, the potential issue of coercion could arise. Even after providing both verbal and written consent, the patient may not clearly understand or appreciate its ramifications. Thus, providing an opportunity for the patient to review the potential content and social media platforms before posting them online would be prudent. ${ }^{18}$

\section{Medico-legal issues of social media 'expert opinion'}

As social media posts are available to the public, physicians have an innate ethical responsibility not to mischaracterize or mislead patients regarding acceptable standards of practice. For example, in a study evaluating stroke thrombectomy cases posted on Twitter by physicians, posted cases had higher reperfusion scores and better outcomes than multiple randomized trials. None of the 115 cases posted on social media reported complications, post-procedure hemorrhages, or patient mortality. ${ }^{14}$ Social media serves as a potential advertising mechanism and may help establish an individual or entity's reputation in the community. Therefore, most physicians are unlikely to post cases with complications or poor clinical outcomes. Instead, they are probably much more likely to post successful, complex or technically challenging procedures than routine surgeries. Therefore, social media posts may potentially mischaracterize practice standards to the public and could be interpreted as a source of 'expert opinion' that may have medico-legal implications. Physicians or their associates who elect to post clinical cases on social media should be aware of the potential to mislead the general public regarding acceptable clinical practices, outcomes, and treatments. They should practice sound ethical judgment in tempering posts that inappropriately argue against accepted practice guidelines or evidence based standards. Posting misleading information about a particular physician's performance statistics might also be used against the physician in a malpractice case. For example, the posting could be construed as promising a certain outcome that might not be fulfilled in a particular case. This could then be used to show that the physician misrepresented their outcomes and did not meet their own standard of care in a particular case.

\section{Ethical conundrum of using social media in marketing}

Social media can improve communication with patients and physician peers, enhance professional networking and development, and contribute to public health research and service. ${ }^{21}$ On the other hand, various social media platforms have been used for marketing or advertising to gain public and/or professional popularity. A hospital market research firm reported that $57 \%$ of healthcare consumers indicated social media presence affected their decision for treatment location, and $81 \%$ of healthcare consumers believed hospitals with an active online presence were 'cutting edge'. ${ }^{22}$ Also, $12.5 \%$ of surveyed healthcare organizations reported that they had successfully attracted new patients through social media. ${ }^{23}$ Scientific journals are not exempt from adopting social media to expand their online access and popularity building. ${ }^{24}$

Ethical considerations of posting patient-related content online are not only limited by 'legal' or regulatory statutes, but by 'professionalism' which requires self-discipline and fidelity. ${ }^{18}{ }^{25}$ The American College of Physicians and the Federation of State Medical Boards stated that maintaining trust in the profession and patient-physician relationship requires that physicians consistently apply ethical principles for preserving the relationship, confidentiality, privacy, and respect for persons to online settings and communications. ${ }^{26}$
'Medutainment' is a term that blends 'medicine', 'education' and 'entertainment', ${ }^{27}$ and is often used to increase personal or institutional notoriety, to attract patients to a clinical practice, or to promote a product. ${ }^{18}$ Many neurointerventional cases have a dramatic clinical story and sensational medical images. Thus, posting neurointerventional cases on social media can easily be manipulated for 'medutainment', ${ }^{27}$ and must be actively avoided. In 'cyberspace' or 'the cloud', people say and do things that they would not ordinarily say or do in the 'real' world or in personthis is known as 'online disinhibition'. ${ }^{28}$ Benign disinhibition is represented as showing unusual acts of kindness and generosity. However, toxic disinhibition may include rude language, harsh criticism, anger, hatred, or threats. Neurointerventional surgeons should be aware and abstain from online disinhibition, especially toxic disinhibition when using social media platforms. Care is warranted in responding to online negative reviews. Similarly, it is important to consider state truth-in-advertising laws: overstating credentials or expertise or defaming colleagues or competitors through online criticism is not acceptable.

\section{OPPORTUNITIES AND THE ROAD AHEAD}

The adoption of social media in medicine falls almost expectedly and stereotypically under the axiomatic assumption that new things are inherently flawed. Similar to the almost ubiquitous disclaimer found appended to most published conclusions that individuals are better off with more data and further studies, the current literature is replete with cautionary exhortations of things to avoid. ${ }^{29}$ While perhaps not well studied, it is also abundantly clear that these technologies play an emerging and, in some instances, a dominant role as an information channel for lifelong learning, peer and patient engagement, benchmarking opinions, enhancing professional networking and communication, and as increasingly important research tools. ${ }^{30} 31$ External factors such as the global pandemic have only appeared to accelerate these changes. Almost all medical students use social media, implying that in a few years most practicing physicians will have at least had significant exposure. ${ }^{32}$

\section{CONCLUSIONS}

Neurointerventional surgeons should capitalize on the tremendous potential that social media can provide for patient engagement, education, practice development, professional networking and collaborations. However, at the same time, he/she should respect the traditional and professional principles of medical ethics. The core value of the central principles of medical ethics includes a dedication to providing competent medical care, adhering to best practice guidelines, respect for human dignity, honesty in all professional interactions, and respect for the rights of patients, colleagues, and other health professionals. ${ }^{33}$

\section{RECOMMENDATIONS}

1. Be proactively transparent to stakeholders (employer, hospital, colleagues, patients) about your intentions and obtain necessary permissions before you initiate social media interactions.

2. Recognize that in discussing professional matters on social media, your reputation and that of your institution are directly or indirectly at risk.

3. Avoid obvious pitfalls (eg, HIPAA, PHI) such as time and circumstance leading to identifiable situations. Identify whether your local environment requires consent for posting nonidentifiable information. 
4. Consider potential unintended consequences of a post (eg, patient/family or medico-legal risks).

5. Respect patient or family requests to remove or take down posts.

6. Avoid conflicts of interest such as implied endorsement of products or as a marketing tool, provide disclosures with transparency.

\section{Author affiliations \\ ${ }^{1}$ Neurosurgery, Wake Forest University, Winston-Salem, North Carolina, USA \\ ${ }^{2}$ Radiology, Montefiore Hospital and Medical Center, Bronx, New York, USA \\ ${ }^{3}$ Neurosurgery, University of South Florida, Tampa, Florida, USA \\ ${ }^{4}$ Interventional Neuroradiology, Abbot Northwestern Hospital, Minneapolis, Minnesota, USA \\ ${ }^{5}$ Neurosurgery, Icahn School of Medicine at Mount Sinai, New York, New York, USA \\ ${ }^{6}$ Neurology and Neurosurgery, Westchester Medical Center, Valhalla, New York, USA \\ ${ }^{7}$ Radiology, Northwestern University Feinberg School of Medicine, Chicago, Illinois, \\ USA \\ ${ }^{8}$ Neurosurgery, Montefiore Hospital and Medical Center, Bronx, New York, USA \\ ${ }^{9}$ Neurological Surgery, University of Cincinnati, Cincinnati, Ohio, USA \\ ${ }^{10}$ Neurosurgery, Geisinger Health System, Wilkes-Barre, Pennsylvania, USA \\ ${ }^{11}$ Neurological Surgery, University of Kentucky, Lexington, Kentucky, USA \\ ${ }^{12}$ Radiology and Biomedical Imaging, University of California San Francisco, San \\ Francisco, California, USA}

\section{Twitter Reade De Leacy @rdeleacymd}

Collaborators SNIS Standards and Guidelines Committee: Fawaz Al-Mufti, Sameer Ansari, Ketan Bulsara, Reade De Leacy, Steven W. Hetts, Seon-Kyu Lee, Charles Prestigiacomo, Clemens Schirmer, Robert Starke. SNIS Board of Directors: Felipe C. Albuquerque, Sameer Ansari, Adam S. Arthur, Blaise W. Baxter, Michael Chen, Guilherme Dabus, Justin F. Fraser, Johanna T. Fifi, Michael T. Froehler, Mahesh Jayaraman, Richard P. Kluznick, William J. Mack, James M. Milburn, J Mocco, Ansaar T. Rai, Adnan Siddiqui.

Contributors All authors contributed to the writing and editing of this standards document.

Funding The authors have not declared a specific grant for this research from any funding agency in the public, commercial or not-for-profit sectors.

Disclaimer This literature review is provided for informational and educational purposes only. It is not intended to provide either legal, medical, or ethical advice. Adherence to any recommendations included in this review will not ensure compliance with applicable laws, regulations, or professional standards. Furthermore, the recommendations contained in this review and its conclusions and recommendations reflect the best available information when the review was prepared. SNIS does not warrant the review's accuracy or completeness of the information presented herein and assumes no responsibility for any errors or omissions.

Competing interests None declared.

Patient consent for publication Not required.

Provenance and peer review Not commissioned; externally peer reviewed.

ORCID iDs

Maxim Mokin http://orcid.org/0000-0003-4270-8667

Reade De Leacy http://orcid.org/0000-0001-9447-5338

Clemens M Schirmer http://orcid.org/0000-0003-1743-8781

Justin F Fraser http://orcid.org/0000-0002-5980-3989

Steven W Hetts http://orcid.org/0000-0001-5885-7259

\section{REFERENCES}

1 Boyd D, Ellison NB. Social network sites: definition, history, and scholarship. Journal of Computer-Mediated Communication 2007;13:210-30.

2 Perrin AAM. Share of U.S. adults using social media, including Facebook, is mostly unchanged since 2018. Pew research center, 2019. Available: https://www. pewresearch.org/fact-tank/2019/04/10/share-of-u-s-adults-using-social-mediaincluding-facebook-is-mostly-unchanged-since-2018/
3 Alotaibi NM, Guha D, Fallah A, et al. Social media metrics and bibliometric profiles of neurosurgical departments and journals: is there a relationship? World Neurosurg 2016;90:574-9.

4 Stroke-Home S. Facebook. Available: https://wwwfacebookcom/survivestroke/ [Accessed 1 Feb 2020].

5 Sterling M, Leung P, Wright $\mathrm{D}$, et al. The use of social media in graduate medical education: a systematic review. Acad Med 2017;92:1043-56.

6 Carley S, Beardsell I, May N, et al. Social-media-enabled learning in emergency medicine: a case study of the growth, engagement and impact of a free open access medical education blog. Postgrad Med J 2018;94:92-6.

7 Eli K. Is ResearchGate Facebook for science? 2014. Available: https:/l wwwsciencemagorg/careers/2014/08/researchgate-facebook-science [Accessed 01 Feb 2020].

8 O'Brien K, O'Brien K. ResearchGate. Jmla 2019;107:284-5.

9 Lifchez SD, McKee DM, Raven RB, et al. Guidelines for ethical and professional use of social media in a hand surgery practice. J Hand Surg Am 2012;37:2636-41.

10 Ehlert MJ, Media S. Social media and online communication: clinical urology practice in the 21st century. Urol Pract 2015;2:2-6.

11 Mata DA, Tilak G, Loeb S, et al. Curating a digital identity: what urologists need to know about social media. Urology 2016;97:5-7.

12 Landman MP, Shelton J, Kauffmann RM, et al. Guidelines for maintaining a professional COMPASS in the era of social networking. J Surg Educ 2010;67:381-6.

13 Shore R, Halsey J, Shah K, et al. Report of the AMA Council on ethical and judicial affairs: professionalism in the use of social media. J Clin Ethics 2011:22:165-72.

14 Dmytriw AA, Sorenson TJ, Morris JM, et al. \#Fake news: a systematic review of mechanical thrombectomy results among neurointerventional stroke surgeons on Twitter. J Neurointerv Surg 2019;11:460-3.

15 Services UDoHaH. Guidance regarding methods for de-identification of protected health information in accordance with the Health Insurance Portability and Accountability Act (HIPAA) privacy rule, 2015. Available: https://wwwhhsgov/hipaa/ for-professionals/privacy/special-topics/de-identification/indexhtml [Accessed 02 Dec 2017].

16 Greysen SR, Johnson D, Kind T, et al. Online professionalism investigations by state medical boards: first, do no harm. Ann Intern Med 2013;158:124-30.

17 Rimmer A. Doctors' use of Facebook, Twitter, and WhatsApp is the focus of $28 \mathrm{GMC}$ investigations. BMJ 2017;358:j4099.

18 Bennett KG, Vercler CJ. When Is posting about patients on social media unethical "medutainment"? AMA J Ethics 2018;20:328-35.

19 Thaker SI, Nowacki AS, Mehta NB, et al. How U.S. hospitals use social media. Ann Intern Med 2011;154:707-8.

20 Northwestern.edu. Social media guidelines. Available: https://www.feinberg. northwestern.edu/communications/guidelines/social-media.html

21 George DR, Rovniak LS, Kraschnewski JL. Dangers and opportunities for social media in medicine. Clin Obstet Gynecol 2013;56:453-62.

22 Peck JL. Social media in nursing education: responsible integration for meaningful use J Nurs Educ 2014;53:164-9.

23 Househ M. The use of social media in healthcare: organizational, clinical, and patient perspectives. Stud Health Technol Inform 2013:183:244-8.

24 Jadhav AP, Ducruet AF, de Leacy R, et al. Social media and predictors of traditional citations: insights from the Journal of Neurointerventional surgery. J Neurointerv Surg 2019;11:99-100

25 Sabin JE, Harland JC. Professional ethics for digital age psychiatry: boundaries, privacy, and communication. Curr Psychiatry Rep 2017:19:55.

26 Farnan JM, Snyder Sulmasy L, Worster BK, et al. Online medical professionalism: patient and public relationships: policy statement from the American College of Physicians and the Federation of State Medical Boards. Ann Intern Med 2013;158:620-7.

27 S C. \#Medutainment and emergency medicine. Part 1 . What is it and where did it come from? 2015. Available: http://stemlynsblogorg/medutainment-and-emergencymedicine-part-1- what-is-it-and-where-did-it-come-from/ [Accessed 20 Jun 2020].

28 Suler J. The online disinhibition effect. Cyberpsychol Behav 2004;7:321-6.

29 George DR, Green MJ. Beyond good and evil: exploring medical trainee use of social media. Teach Learn Med 2012;24:155-7.

30 Atherton H, Majeed A. Social networking and health. Lancet 2011:377:2083.

31 Chen M, Mangubat E, Ouyang B. Patient-reported outcome measures for patients with cerebral aneurysms acquired via social media: data from a large nationwide sample. J Neurointerv Surg 2016;8:42-6.

32 Bosslet GT, Torke AM, Hickman SE, et al. The patient-doctor relationship and online social networks: results of a national survey. J Gen Intern Med 2011;26:1168-74.

33 American Medical Association. AMA principles of medical ethics. Available: https:// www.ama-assn.org/about/publications-newsletters/ama-principles-medical-ethics [Accessed 21 Jun 2020] 